\title{
Serum Insulin and Insulin Resistance in the Off-Springs of Type 2 Diabetes Mellitus
}

Meraj Rahim ${ }^{1}$, Mariam Rahim ${ }^{2}$, Masood Anwar Qureshi ${ }^{1}$, Shaheen Sharafat ${ }^{3}$, Zaman Shaikh ${ }^{4}$, Munim Abdul Rahim ${ }^{5}$ and Mubashir Zafar ${ }^{6}$

${ }^{1}$ Department of Physiology Dow University of Health Sciences, Pakistan

${ }^{2}$ Final year MBBS student, Dow Medical College, Dow University of Health Sciences, Pakistan

${ }^{3}$ Department of Microbiology, Dow University of Health Sciences, Pakistan

${ }^{4}$ Department of Medicine, Dow University of Health Sciences, Pakistan

5 Institute of Isharat ul ebad of oral health sciences, Dow university of Health Sciences, Pakistan

${ }^{6}$ School of Public Health, Dow University of Health Sciences, Pakistan

\begin{abstract}
Background: Type 2 diabetes mellitus has become a universal problem. Globally $80 \%$ of lower and middle income countries are suffering from diabetes.
\end{abstract}

Aims: To determine the levels of serum insulin and to assess the insulin resistance in the offspring of diabetic parents as the predicting factors of Type 2 diabetes.

Material and Methods: It is a cross-sectional study. The subjects were classified by their family history of T2DM; those with Single Diabetic Parent (SDP), Both Diabetic Parents (BDP) and No Diabetic Parents (NDP). Fasting blood sugar levels were determined by glucose oxidase and serum insulin by chemi luminescent immunometric assay. Insulin resistance was assessed by HOMA-IR index.

Results: Fasting glucose was within normal range. Mean values for fasting serum Insulin levels of three groups of subjects though fell within the normal range but the levels both in SDP and BDP were significantly higher (P 0.05) than NDP.

Conclusions: Hyperinsulinemia seems a predicting factor of T2DM in subjects who have a history of diabetes in parents.

Keywords: Diabetes; Family history; Insulin resistance

\section{Introduction}

Type 2 diabetes mellitus has become a universal problem. Globally $80 \%$ of lower and middle income countries are suffering from it [1]. Pakistan is ranked 6th amongst the top 10 countries of the world including India, China and USA in the report predicting cases of diabetes for the future: the number of estimated cases with diabetes in Pakistan were 5.2 million in 2000 and projected to be 13.9 million in 2030 [2].

Prevalence of Diabetes Mellitus (DM) and Impaired Glucose Tolerance (IGT) among the urban Pakistani population is $6.0 \%$ in men and $3.5 \%$ in women [3]. Furthermore, family history of diabetes and occurence of obesity in Sindh reflects a positive correlation with both fasting and insulin levels [4]. In developed world, obesity of youth is increasing in an alarming rate and since three decades it has tripled $[5,6]$.

Impaired glucose metabolism due to Insulin Resistance is associated with obesity [7-10]. In IR, the target tissues are not responsive to the action of insulin hence the islet cells get hypertrophied which produce to hyperinsulinemia will lead to decreased serum glucose levels [11]. IR and obesity are associated with increase body mass leading to increase in BMI, waist circumference and waist to hip ratio $[12,13]$.

Pathological and etiological factors for DM have been extensively studied but the precise mechanism(s) still remains unclear. It is now considered amongst one of the major diseases with multifactorial genetic as well as environmental pattern of inheritance based on familial clustering [2]. Thus, there is a genetic factor, which is worsened by insulin resistance, sedentary lifestyle and visceral obesity [14]. Family history which is an important component for future diabetes represents a backbone for the genetic background [15]. Transmission of genes to the offspring occurs by parental history which also is a significant risk factor for diabetes in future $[16,17]$. A greater probability to acquire T2DM was seen among offspring of single diabetic parents and offspring of both diabetic parents compared to those of non-diabetic parents in Framingham population [18,19]. Offsprings of FHD (Family history of diabetes) showed an increased risk in western world [20,21] with an age range of 35-45 year olds except that there are few studies in young asian offspring [22].

\section{Methods}

\section{Objective}

The objective of this research is to determine the insulin resistance in subjects having single or both diabetic parents.

\section{Methodology}

Study area, design and period: Young healthy subjects aged between 18-24 yrs were recruited from different campuses of Dow University of Health Sciences Karachi, (DUHS) e.g. National Institute of Diabetes and Endocrinology (NIDE), Dow College of Pharmacy and Institute

*Corresponding author: Dr. Meraj Rahim, Assistant Professor of Physiology Department of Physiology, Dow University of Health Sciences, Karachi, Pakistan, Tel: 92-2134014774; E-mail: meraj.rahim@duhs.edu.pk

Received June 09, 2014; Accepted August 31, 2014; Published September 08 2014

Citation: Rahim M, Rahim M, Qureshi MA, Sharafat S, Shaikh Z, et al. (2014) Serum Insulin and Insulin Resistance in the Off-Springs of Type 2 Diabetes Mellitus. J Diabetes Metab 5: 425 doi:10.4172/2155-6156.1000425

Copyright: ( 2014 Rahim M, et al. This is an open-access article distributed under the terms of the Creative Commons Attribution License, which permits unrestricted use, distribution, and reproduction in any medium, provided the original author and source are credited. 
Citation: Rahim M, Rahim M, Qureshi MA, Sharafat S, Shaikh Z, et al. (2014) Serum Insulin and Insulin Resistance in the Off-Springs of Type 2 Diabetes Mellitus. J Diabetes Metab 5: 425 doi:10.4172/2155-6156.1000425

Page 2 of 5

of Nursing. Cross-sectional study was conducted and the subjects were classified according to their parent's family history, as follows:
Group I:
NDP (offspring of no diabetic parent)
Group II:
SDP (offspring of single diabetic parent)
Group III:
$\mathrm{BDP}$ (offspring of both diabetic parents)

The study was carried from 2010 to 2011.

Sample collection technique: Non probability sampling and convenient sampling

Sample size: Sample size is 180 , calculated for a confidence interval of $95 \%$ and a $5 \%$ margin of error. It was estimated by taking the percentage frequency of diabetes as $13.5 \%$ in our population [23].

Instrument and data collection: In this study the inclusion criteria were healthy young adults' age between 18-24 years with no history of medical problems or any recent or remote diseases. All participants who had NDP (No T2DM Parents), SDP (Single T2DM Parent) BDP (Both Diabetic Parents) Exclusion criteria were subjects with $\mathrm{H} / \mathrm{O}$ diabetes or any known endocrinopathies.

Theme of the study was explained and written consent was taken from the volunteers prior to data collection. A predesigned questionnaire was provided to the subjects with the following required fields: age, gender, history of diabetes.

The offspring with father or mother having T2DM was placed under group SDP, whereas the one with both parents having T2DM was placed under group BDP. While those showing no family history of T2DM was considered as NDP.

The participants were instructed to come in fasting condition (12 hrs) to Dow Diagnostic Research Laboratories (DDRL) Ojha Campus. Batch of 20 subjects were inducted each time for anthropometric measurements (Height, Weight, Waist-Hip circumference) and blood collection (12 ml). After withdrawal of blood, a juice and biscuit pack were provided to them. Metabolic and hormonal parameters were Fasting plasma glucose (mg/ $\mathrm{dl})$, Fasting Insulin $(\mu \mathrm{U} / \mathrm{ml})$ and Homa-Insulin Resistance Index=Fasting Insulin $\mathrm{x}$ Fasting Plasma glucose/22.5 [24].

By using the standard procedures both biochemical parameters were assessed. Plasma Glucose levels were estimated by glucose oxidase method via photometric technique. The blood was centrifuged in HERMLE 2323 centrifuge for 10 minutes and shifted to ROCHE HITACHI 902 automated analyzer.
Distilled water $(4 \mathrm{ml})$ was added and gently mixed then analyzed. Insulin was estimated using Immulite 1000 Analyzers (Siemens Medical Solutions Diagnostics), a fully automated instrument requiring minimal manual interference. The working principle of the immulite insulin 1000 is a solid phase, two sites Chemiluminescent Immunometric Assay (CIA).

\section{Data management and analysis}

Data was entered and analyzed using SPSS16.0, Mean was compared across all three groups using one way anova (ANOVA) after findings of significance of ANOVA, a multiple comparison between pair of means were made using the Scheffe method of pair wise comparison, a p-value $<0.05$ was considered as significant as differences in means of two groups.

Pearson correlation was used to see the correlations among age BMI, HOMA- IR and serum Insulin, among all three groups independently, a correlation test $\mathrm{p}$-value $<0.05$ considered as significant correlation between two parameters,

Bar charts were used to display the means and percentages across the three study groups (Table 2).

\section{Ethical consideration}

The study was approved by ethical committee of Dow University of Health Sciences Karachi Pakistan. Consent was also taken from Institutional Review Board. Grant for research was given by the institution.

\section{Results}

The Body Weight (B.W) of offspring BDP versus NDP was significantly higher $(p<0.05)$ and offspring of SDP versus BDP make no difference. The mean value for BMI was $25.58 \pm 5.15$ in BPD, 22.26 \pm 6.80 in SDP, and $21.02 \pm 6.19$ in NDP (Table 1). However BMI mean of offspring of both groups (BDP \& SDP) was significantly greater than offspring of NDP (Table 1). In Figure 1 the frequency of underweight

\begin{tabular}{|l|c|c|c|c|c|c|}
\hline Parameters & \multicolumn{2}{|c|}{$\begin{array}{c}\text { BDP } \\
\mathrm{n}=39\end{array}$} & \multicolumn{2}{c|}{$\begin{array}{c}\text { SDP } \\
\mathrm{n}=71\end{array}$} & \multicolumn{2}{c|}{$\begin{array}{c}\text { NDP } \\
\mathrm{n}=70\end{array}$} \\
\hline Body Weight $(\mathrm{Kg})$ & \multicolumn{2}{|c|}{$70.38 \pm 10.78$} & \multicolumn{2}{|c|}{$57.27 \pm 14.33$} & \multicolumn{2}{|c|}{$57.03 \pm 10.17$} \\
\hline BMI (Kg/m2) & \multicolumn{2}{|c|}{$25.58 \pm 5.15$} & \multicolumn{2}{|c|}{$22.26 \pm 6.80$} & \multicolumn{2}{|c|}{$21.02 \pm 6.19$} \\
\hline Waist /Hip Ratio & Male & Female & Male & Female & Male & Female \\
\cline { 2 - 7 } At High Risk & $14.3 \%$ & 37.5 & $23.1 \%$ & $30.4 \%$ & Nil & Nil \\
\hline
\end{tabular}

Table 1: Physical characteristics of offspring of BDP.SDP \& NDP

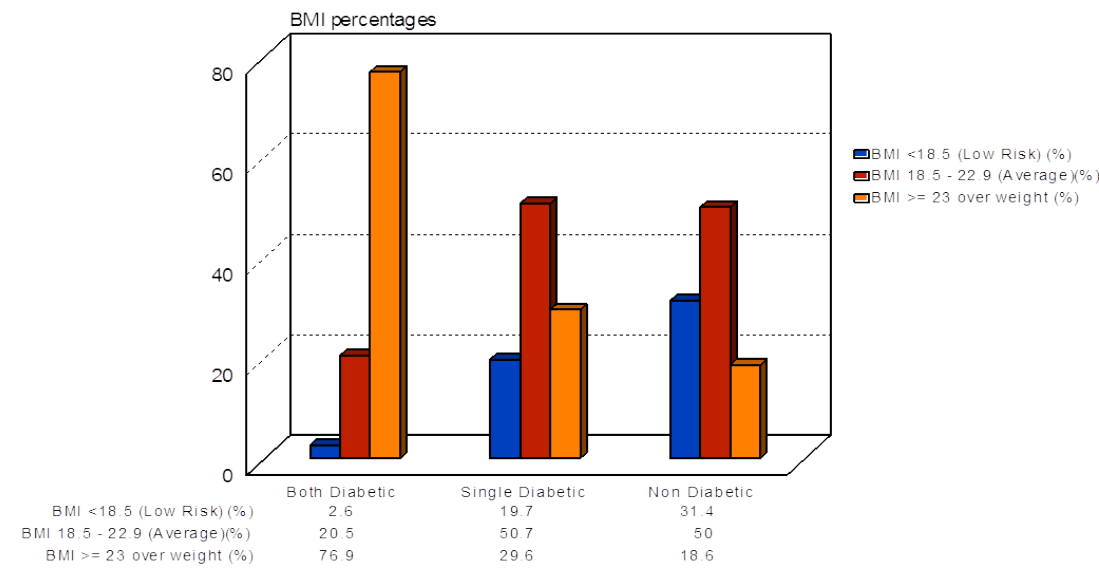

Figure 1: BMI\% in the 3 groups. 
Citation: Rahim M, Rahim M, Qureshi MA, Sharafat S, Shaikh Z, et al. (2014) Serum Insulin and Insulin Resistance in the Off-Springs of Type 2 Diabetes Mellitus. J Diabetes Metab 5: 425 doi:10.4172/2155-6156.1000425

Page 3 of 5

$(\mathrm{BMI}<18.5 \%)$ in offspring of BDP, SDP and NDP was 2.6, 19.7 and 31.4 , in normal weight (BMI, 18.5-22.9) it was 20.5, 50.7 and 50 and in overweight $(\mathrm{BMI} \geq 23)$ it was $76.9,29.6$ and 18.6 respectively. BDP offspring showed high risk for males i.e.14.35\%, $37.50 \%$ for females, and SDP offspring had $23.1 \%$ in males and $30.4 \%$ in females, whereas offspring of NDP had a normal WHR(Waist hip ratio) (Table 1). BMI and WHR were calculated by Asian Pacific cutoffs [25-27].

Fasting Plasma Glucose levels were in normal range in all three groups but the mean FPG level was higher in BDP as compared to SDP and NDP (Table 1).

In present study impaired fasting glucose was detected in $5.1 \%$ and $4.2 \%$ in offspring of BDP and SDP respectively (Figure 2). The criterion was according to DDRL \{Dow lab\} Fasting Plasma glucose is $<100$

\begin{tabular}{|l|c|c|c|}
\hline Parameters & $\begin{array}{c}\text { BDP } \\
n=39\end{array}$ & $\begin{array}{c}\text { SDP } \\
n=71\end{array}$ & $\begin{array}{c}\text { NDP } \\
n=70\end{array}$ \\
\hline Fasting Plasma Glucose (Mean(SD)) & $4.73 \pm 0.75$ & $4.65 \pm 0.47$ & $4.61 \pm 0.24$ \\
\hline Serum Insulin (Mean(SD)) & $8.36 \pm 5.13$ & $5.90 \pm 2.75$ & $6.42 \pm 2.61$ \\
\hline HOMA IR (Mean(SD)) & $2.4 \pm 2.08$ & $1.31 \pm 0.85$ & $1.31 \pm 0.51$ \\
\hline
\end{tabular}

Table 2: Biochemical parameters of offspring of BDP.SDP \& NDP.

\begin{tabular}{|l|c|c|c|}
\hline Parameters & $\begin{array}{c}\text { NDPVS SDP } \\
\text { p-value }\end{array}$ & $\begin{array}{c}\text { NDPVS BDP } \\
\text { p-value }\end{array}$ & $\begin{array}{c}\text { SDPVS BDP } \\
p \text {-value }\end{array}$ \\
\hline Body Weight $(\mathrm{Kg})$ & 0.994 & $0.00<0.05$ & $0.00<0.05$ \\
\hline $\mathrm{BMI}(\mathrm{Kg} / \mathrm{m} 2)$ & 0.537 & $0.005>0.05$ & 0.056 \\
\hline FPG $(\mathrm{mmol} / \mathrm{l})$ & 0.701 & 0.451 & 0.874 \\
\hline Insulin $(\mu \mathrm{U} / \mathrm{ml})$ & 0.617 & $0.016<0.05$ & $0.002<0.05$ \\
\hline HOMA IR & 1 & $0.005<0.05$ & $0.00<0.05$ \\
\hline
\end{tabular}

Table 3: Sheffe' multiple pair wise comparison of physical and biochemical parameters.

\begin{tabular}{|c|c|c|c|c|c|c|}
\hline \multirow{2}{*}{$\begin{array}{l}\text { Parameters } \\
\text { Age-HOMA IR }\end{array}$} & \multicolumn{2}{|c|}{$\begin{array}{c}\text { NDP } \\
r \text { p-value }\end{array}$} & \multicolumn{2}{|c|}{$\begin{array}{c}\text { SDP } \\
\text { r p-value }\end{array}$} & \multicolumn{2}{|c|}{$\begin{array}{l}\text { BDP } \\
\mathrm{r} \text { p-value }\end{array}$} \\
\hline & 0.14 & 0.234 & 0.067 & 0.577 & 0.118 & 0.475 \\
\hline BMI-HOMA IR & 0.198 & 0.144 & 0.4 & $.001<0.05$ & 0.165 & 0.37 \\
\hline Serum Insulin-HOMA-IR & 0.92 & $\begin{array}{l}<0.01 \\
97\end{array}$ & $<0.01$ & 0.97 & \multicolumn{2}{|c|}{$<0.001$} \\
\hline Serum Insulin-BMI & -0.30 & $<0.01$ & 0.11 & 0.35 & 0.05 & 0.77 \\
\hline
\end{tabular}

Table 4: Intragroup correlations in anthropometric and biochemical parameters. $\mathrm{mg} / \mathrm{dl}$. Mean fasting Insulin in offspring of BDP, SDP and NDP were $8.61 \pm 5.13,5.90 \pm 2.75$ and $6.42 \pm 2.61$ (Table 1). There was significant difference in insulin levels in between NDP versus BDP and SDP versus $\mathrm{BDP}$ that is $\mathrm{p}<0.05$ (Table 3 ).

The Insulin Resistance as assessed by HOMA-IR was statistically significant $(\mathrm{p}<0.05)$ in NDP versus BDP and SDP versus BDP (Table 3$)$.

Table 4 shows intragroup correlations in anthropometric and biochemical parameters have -no correlation was found but in BMIHOMA-IR p-value was found to be $<0.05$ in SDP as compared to BDP and Serum Insulin -HOMA-IR had a positive correlation in all three groups but the $\mathrm{p}$-value was significant that is less than $<0.001$ in BDP off springs.

\section{Discussions}

The present study was carried out among offspring of diabetic parents to detect hyperinsulinemia and insulin resistance at an early stage in life which can help to establish measures for preventing the development of T2DM so that lifestyle modifications (dietary habits, exercise and weight loss) are accordingly advised to such individuals. Such information about the influence of history of DM on the offspring of diabetic patients (single or both) in relation to the metabolic risk factors is scarce, particularly in this part of the world.

Shahid et al. [28] found that the offspring of single and both diabetic parents were increased prevalence of certain metabolic risk factors which may trigger or perpetuate the development of diabetes and/or cardiovascular disorders. It documented that offspring of patients T2DM when compared to normal individuals having no family history of T2DM and matched for sex, age and BMI, in addition to hyperinsulinemia, had higher fasting serum triglycerides, LDLcholesterol and higher IR index. The study conducted in Lahore also documented that offspring of T2DM are associated with increased predicting factors for developing diabetes [28]. This is consistent with a study carried out in the European population [28] as well as the only study conducted in Pakistan which involved male offspring as subjects [29]. Thus, the results of this study are in concurrence with their study except that the results of our study are based on both male and female offspring of single and both diabetic patients, frequency of female was higher in offspring of SDP as contrast to the previous study which found

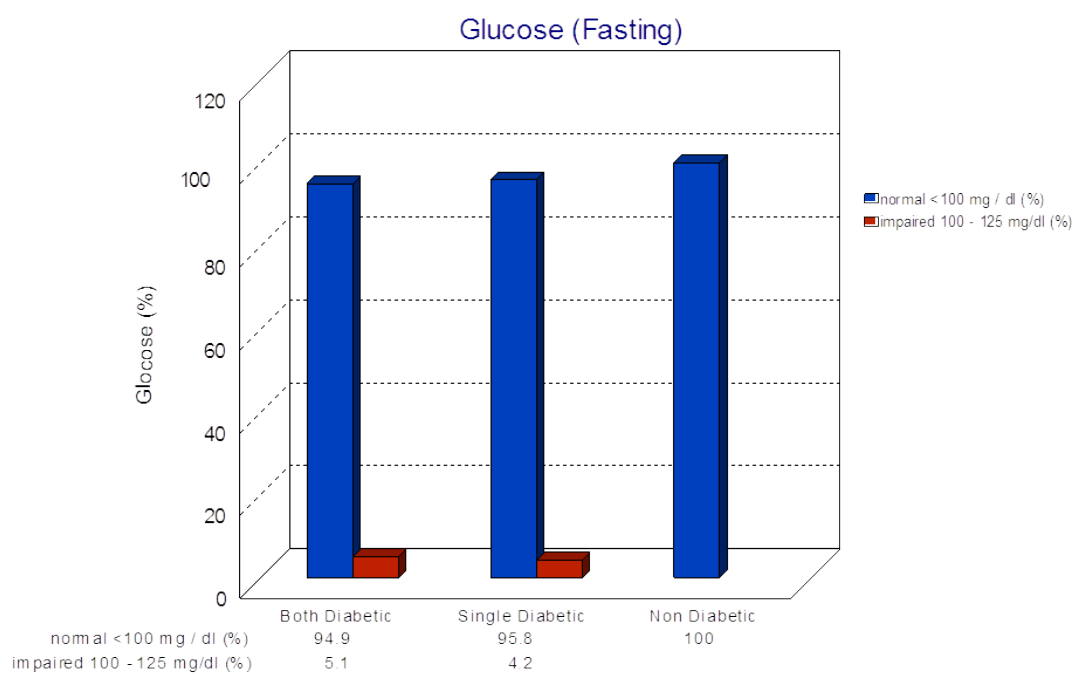

Figure 2: Fasting Plasma Glucose (\%) in BPD, SDP and NDP. Serum Insulin $\%$ in the 3 groups (BDP, SDP and NDP). 
Citation: Rahim M, Rahim M, Qureshi MA, Sharafat S, Shaikh Z, et al. (2014) Serum Insulin and Insulin Resistance in the Off-Springs of Type 2 Diabetes Mellitus. J Diabetes Metab 5: 425 doi:10.4172/2155-6156.1000425

Page 4 of 5

the influence of positive family history of T2DM in only male offspring. T2D has been diagnosed in about $45 \%$ of youth who gave history of IR [30-32]. Previously, higher BMI values were related to higher insulin resistance $[33,34]$.

Sinha et al. [33] has reported importance of family history of diabetes in depicting the predicting factors like IR and raised BMI inspite of normal glucose. Unger et al. [35] found the mean values of weight and BMI which were significantly higher in the subjects who gave a positive history of diabetes in a single parent or both parents. In another study people with diabetes had higher mean body weight, BMI, WHR and percentage of body fat than those individuals without diabetes [35]. Presently it was studied that females have a higher IR than males because the BMI and waist circumference was also higher in females as compared to males [36]. Recently in a study it was assessed that waist circumference was an excellent predictor of Insulin Resistance, as it denotes central adiposity besides other anthropometric measurement [37].

In a current study it was assessed that those who gave a FHD had a greater BMI, WC and WHR are at higher risk of developing diabetes [38]. The study presented here thus documented the values of certain anthropometric variables like BW, WHR and BMI, known to influence carbohydrate and lipid metabolisms and indirectly the T2 $\mathrm{DM}$ and suggests some of these as potential risk factors of this disease at young age. The increased weight suggests hyperinsulinemia among the offspring of diabetic patients compared to corresponding controls. The present study thus provides additional information regarding the influence of family history of diabetes on the frequency of gender in the offspring as well points strongly to the role of genetic factors as a predisposition of metabolic dysfunction, supported by findings of a common variant of gene for fat, mass and obesity with respect to DM relationship to BMI [39].

Metabolic syndrome is increasing worldwide; most important markers are insulin resistance, visceral and waist circumference and high blood pressure etc. Besides this there are impaired glucose levels and dyslipidemias and different circulating inflammatory cells all leading to diabetes mellitus. Therefore it is advisable to refrain from sedentary life style and opt for a healthy lifestyle [40-46]. There is positive correlation between obesity and diabetes mellitus because of which lifestyle modification is a really important factor governing Diabetes [47-49].

\section{Conclusion}

Hyperinsulinemia governs the predicting factor of T2DM in those subjects who gave a history of diabetes and raised anthropometric measurements like BMI and WHR.

\section{Limitations of Study}

Some limitations ' were seen during the study including: all samples were collected for glucose levels and serum insulin in fasting condition only. All participants who have NDP [No Diabetic Parents], SDP [Single Diabetic Parent], and BDP [Both Diabetic Parents] were included. The data of family history was collected by written questionnaire and verified by the participants but their parent's blood test was not performed. Hence family history record provides an insightful important clue towards the debilitating insidious onset of the disease.

\section{Acknowledgements}

I am grateful to Dow University of Health sciences for giving me the grant and support for research, and also giving me the permission to carry out my study among students of the campus who happen to be of same age groups required in our study.

\section{References}

1. International Diabetes Federation (2011) The Diabetes Atlas. 5th edn (2011) Brussels, Belgium, International Diabetes Federation.

2. Wild S, Roglic G, Green A, Sicree R, King H (2004) Global prevalence of diabetes: estimates for the year 2000 and projections for 2030. Diabetes Care 27: 1047-1053.

3. Shera AS, Jawad F, Maqsood A (2007) Prevalence of diabetes in Pakistan Diabetes Res Clin Pract 76: 219-222.

4. Ahmed MY, Hakeem R, Fawwad A, Basit A, Shera AS (2008) Determination of reference values for elevated fasting and random insulin levels and their associatins with metabolic risk factors among rural Pakistanis from Sindh Province. Metab Syndr Relat Disord 6:143-148.

5. Ogden CL1, Carroll MD, Curtin LR, McDowell MA, Tabak CJ, et al. (2006) Prevalence of overweight and obesity in the United States, 1999-2004. JAMA 295: 1549-1555.

6. World Health Organization.. Obesity and overweight. (2011)

7. Lee JM, Okumura MJ, Davis MM, Herman WH, Gurney JG (2006) Prevalence and determinants of insulin resistance among U.S. adolescents: a populationbased study. Diabetes Care 29: 2427-2432.

8. Li C, Ford ES, Huang TT, Sun SS, Goodman E (2009) Patterns of change in cardiometabolic risk factors associated with the metabolic syndrome among children and adolescents: the Fels Longitudinal Study. J Pediatr 155: S5.

9. Liu BW, Lu Q, Ma CM, Wang SY, Lou DH, et al. (2009) Factors associated with insulin resistance and fasting plasma ghrelin levels in adolescents with obesity and family history of type 2 diabetes. Exp Clin Endocrinol Diabetes 117: $600-604$

10. Monzavi R, Dreimane D, Geffner ME, Braun S, Conrad B, et al. (2006) Improvement in risk factors for metabolic syndrome and insulin resistance in overweight youth who are treated with lifestyle intervention. Pediatrics 117 e1111-1118.

11. (National Diabetes Information Clearinghouse, 2008) National Diabetes Information Clearinghouse. (2008). Insulin resistance and pre-diabetes.

12. Bitsori M, Linardakis M, Tabakaki M, Kafatos $A$ (2009) Waist circumference as a screening tool for the identification of adolescents with the metabolic syndrome phenotype. Int J Pediatr Obes 4: 325-331.

13. Cossio S, Messiah SE, Garibay-Nieto N, Lopez-Mitnik G, Flores P, et al. (2009) How do different indices of obesity correlate with cardiometabolic disease risk factors in multiethnic youths? Endocr Pract 15: 403-409.

14. Masharani U, Karam JH, German MS (2004) Basic \& Clinical Endocrinology, $7^{\text {th }}$ edn.

15. Klein BE, Klein R, Moss SE, Cruickshanks KJ (1996) Parental history of diabetes in a population-based study. Diabetes Care 19: 827-830.

16. Lillioja S, Mott DM, Zawadzki JK, Young AA, Abbott WG, et al. (1987) In vivo insulin action is familial characteristic in nondiabetic Pima Indians. Diabetes 36: 1329-1335.

17. Sakul H, Pratley R, Cardon L, Ravussin E, Mott D, et al. (1997) Familiality of physical and metabolic characteristics that predict the development of noninsulin-dependent diabetes mellitus in Pima Indians. Am J Hum Genet 60: 651 656 .

18. Meigs JB, Cupples LA, Wilson PW (2000) Parental transmission of type 2 diabetes: the Framingham Offspring Study. Diabetes 49: 2201-2207.

19. Sjaarda LA, Michaliszyn SF, Lee S, Tfayli H, Bacha F, et al. (2012) HbA(1c) diagnostic categories and $\hat{I}^{2}$-cell function relative to insulin sensitivity in overweight/obese adolescents. Diabetes Care 35: 2559-2563.

20. Siewert S, Filipuzzi S, Codazzi L, Gonzalez I, Ojeda MS (2007) Impact of metabolic syndrome risk factors in first-degree relatives of type 2 diabetic patients. Rev Diabet Stud 4: 177-184

21. Gong L, Kao WH, Brancati FL, Batts-Turner M, Gary TL (2008) Association between parental history of type 2 diabetes and glycemic control in urban African Americans. Diabetes Care 31: 1773-1776. 
Citation: Rahim M, Rahim M, Qureshi MA, Sharafat S, Shaikh Z, et al. (2014) Serum Insulin and Insulin Resistance in the Off-Springs of Type 2 Diabetes Mellitus. J Diabetes Metab 5: 425 doi:10.4172/2155-6156.1000425

Page 5 of 5

22. Praveen EP, Kulshreshtha B, Khurana ML, Sahoo J, Gupta N, et al. (2011) Low $\mathrm{HDL}$-cholesterol among normal weight, normoglycemic offspring of individuals with type 2 diabetes mellitus. Hormones (Athens) 10: 57-66

23. Shera AS, Rafique G, Khwaja IA, Ara J, Baqai S, et al. (1995) Pakistan national diabetes survey:prevalence of glucose intolerance and associated factors in Shikarpur, Sindh Province. Diabet Med 12: 1116-1121.

24. Matthews DR, Hosker JP, Rudenski AS, Naylor BA, Treacher DF, et al. (1985) Homeostasis model assessment: insulin resistance and beta-cell function from fasting plasma glucose and insulin concentrations in man. Diabetologia 28 412-419.

25. Holl MG, Jaser SS, Womack JA, Jefferson VL, Grey M (2011) Metabolic risk and health behaviors in minority youth at risk for type 2 diabetes. Diabetes Care 34: 193-197.

26. Kuk JL, Ardern Cl (2009) Are metabolically normal but obese individuals at lower risk for all-cause mortality? Diabetes Care 32: 2297-2299.

27. Weisell RC (2002) Body mass index as an indicator of obesity. Asia Pac J Clin Nutr 11 Suppl 8: S681-684.

28. Shahid A, Lone KP, Saeed S, Arslan M (2008) Male offspring of both diabetic parents have higher insulin resistance and serum leptin levels compared to those with one diabetic parent. Hormones (Athens) 7: 313-319.

29. Hunter WA1, Cundy T, Rabone D, Hofman PL, Harris M, et al. (2004) Insulin sensitivity in the offspring of women with type 1 and type 2 diabetes. Diabetes Care 27: 1148-1152.

30. Centers for Disease Control and Prevention. (2010). Children and diabetes.

31. Lee JM, Okumura MJ, Davis MM, Herman WH, Gurney JG (2006) Prevalence and determinants of insulin resistance among U.S. adolescents: a populationbased study. Diabetes Care 29: 2427-2432.

32. Shah AS, Dolan LM, Kimball TR, Gao Z, Khoury PR, et al. (2009) Influence of duration of diabetes, glycemic control,and traditional cardiovascular risk factors on early atherosclerotic vascular changes in adolescents and young adults with Type 2 diabetes. J Clin Endocrinol Metab 94:3740-3745.

33. Reaven P (2004) Metabolic syndrome. J Insur Med 36: 132-142.

34. Sinha R, Fisch G, Teague B, Tamborlane WV, Banyas B, et al. (2002) Prevalence of impaired glucose tolerance among children and adolescents with marked obesity. N Engl J Med 346: 802-810.

35. Unger RH (2003) Lipid overload and overflow: metabolic trauma and the metabolic syndrome. Trends Endocrinol Metab 14: 398-403.
36. Bindler RJ, Bindler RC, Daratha KB (2013) Biological correlates and predictors of insulin resistance among early adolescents. J Pediatr Nurs 28: 20-27.

37. Linked Shobha MV, Ravindra PN, Deepali A (2013) Changes In Anthropometric And Lipid Profile In Healthy Young Offsprings Of Diabetics Are Not Temporally. Int J Med Health Sci 2:1.

38. Rodriguez-Rodriguez E, Palmeros-Exsome C, Lopez-Sobaler A, Ortega RM (2010) Preliminary data on the association between waist circumference and insulin resistance in children without a previous diagnosis. European Journal of Pediatrics, 170: 35-43.

39. Frayling TM, Timpson NJ, Weedon MN, Zeggini E, Freathy RM, et al. (2007) A common variant in the FTO gene is associated with body mass index and predisposes to childhood and adult obesity. Science 316: 889-894.

40. Das UN (2003) A perinatal strategy to prevent coronary heart disease. Nutrition 19: $1022-1027$.

41. Albert MA, Glynn RJ, Ridker PM (2003) Plasma concentration of C-reactive protein and the calculated Framingham Coronary Heart Disease Risk Score. Circulation 108: 161-165.

42. Engström G, Hedblad B, Stavenow L, Lind P, Janzon L, et al. (2003) Inflammation-sensitive plasma proteins are associated with future weight gain Diabetes 52: 2097-2101.

43. Mosca L (2002) C-reactive protein--to screen or not to screen? N Engl J Med 347: 1615-1617.

44. Barzilay JI, Abraham L, Heckbert SR, Cushman M, Kuller LH, et al. (2001) The relation of markers of inflammation to the development of glucose disorders in the elderly: the Cardiovascular Health Study. Diabetes 50: 2384-2389.

45. Das UN (2007) Obesity and its relationship to coronary heart disease. Eur Heart J 28: 2953-2954

46. Das UN (2007) Metabolic syndrome $X$ is a low-grade systemic inflammatory condition with its origins in the perinatal period. Current Nutrition and Food Science 3:277-295

47. Das UN (2006) Exercise and inflammation. Eur Heart J 27: 1385

48. Das UN (2004) Anti-inflammatory nature of exercise. Nutrition 20: 323-326.

49. Burke GL, Savage PJ, Sprafka JM, Selby JV, Jacobs DR Jr, et al. (1991) Relation of risk factor levels in young adulthood to parental history of disease. The CARDIA study. Circulation 84: 1176-1187. 